\title{
Oral styletted intubation under video control in a patient with a large mobile glottic tumour and a difficult airway
}

\author{
[L'intubation orale avec un stylet vidéoguidé chez un patient présentant une \\ importante tumeur mobile de la glotte et une intubation difficile]
}

Ichiro Takenaka MD, * Kazuyoshi Aoyama MD, $†$ Motohiro Nakamura MD, ${ }^{*}$ Hiroshi Fukuyama MD, * Yasunari Urakami MD, ${ }^{*}$ Yukari Takenaka MD, $\ddagger$ Tatsuo Kadoya MD*

Purpose: With fibreoptic intubation, advancement of the endotracheal tube (ETT) through the glottis is blind. Thus, in patients with a laryngeal tumour, there is a potential for damage to the tumour. Previously, we proposed the use of a fibreoptic bronchoscope (FOB)-video camera system to permit visualization of tube passage. We used this technique successfully in a patient with a known difficult airway and a large glottic tumour.

Clinical features: A 6I-yr-old man with a known history of difficult laryngoscopic intubation underwent laryngeal microsurgery for recurrence of a glottic tumour. As preoperative indirect laryngoscopy revealed a large, mobile, and pedunculated glottic lesion obstructing the glottic opening, we planned a conventional awake fibreoptic intubation. Endoscopy showed that the tumour partially obstructed the glottis and the space between the tumour and the glottic opening was very narrow. To avoid damage to the tumour, we changed to an alternative fibreoptic intubation technique. The FOB attached to a video camera was passed nasally and a jaw thrust manoeuver was applied, providing an excellent view of the larynx. An anesthesiologist inserted the ETT with a curved stylet orally, and carefully advanced the tube tip into the space between the tumour and the glottic opening under video control. Absence of damage to the tumour and passage of the tube between the cords were confirmed visually.

Conclusion: This alternative intubation technique, providing a view of the tube passage into the glottis, was a reasonable method to avoid potential damage to the glottic tumour by blind tube passage during conventional fibreoptic intubation.
Objectif : Pendant l'intubation fibroscopique, la poussée du tube endotrachéal (TET) au travers de la glotte se fait à l'aveugle. En présence d'une tumeur laryngée, il y a donc une possibilité d'altérer la tumeur. Auparavant, nous avons proposé d'utiliser un fibroscope bronchique (FOB) guidé par une caméra vidéo, ce qui permet de visualiser le passage du tube. Cette technique a été utilisée avec succès chez un patient connu pour problèmes d'intubation et qui présentait une tumeur glottique.

Éléments cliniques : Un homme de 61 ans connu pour des problèmes d'intubation a subi une intervention au larynx en microchirurgie pour une tumeur récidivante. Comme la laryngoscopie indirecte préopératoire révélait une importante lésion pédiculée et mobile obstruant l'ouverture glottique, nous avons planifié une intubation fibroscopique vigile traditionnelle. L'endoscopie a montré que la tumeur obstruait partiellement la glotte et que l'espace entre la tumeur et l'ouverture glottique était très étroite. Nous avons donc opté pour une intubation fibroscopique modifiée afin de ne pas toucher à la tumeur. Le FOB, relié à une caméra vidéo, a été passé par voie nasale et une manœurre de projection de la mandibule a été appliquée pour favoriser une meilleure visualisation du larynx. Un anesthésiologiste a inséré un TET avec un stylet courbé par voie orale et, sous contrôle vidéo, a poussé prudemment la pointe du tube dans l'espace entre la tumeur et l'ouverture glottique. Le système de caméra vidéo a permis de confirmer l'absence de dommage à la tumeur et le passage du tube entre les cordes vocales.

Conclusion : La technique d'intubation décrite, qui fournit une visualisation du passage du tube dans la glotte, s'est révélée satisfaisante pour éviter de toucher la tumeur glottique par le passage du tube à l'aveugle pendant l'intubation fibroscopique traditionnelle.

From the Departments of Anesthesia, Nippon Steel Yawata Memorial Hospital, ${ }^{\star}$ the Moji Rosai Hospital, $†$ and the Emergency Life Saving Technique Academy, $\ddagger$ Kitakyushu, Japan.

Address correspondence to: Dr. Ichiro Takenaka, Department of Anesthesia, Nippon Steel Yawata Memorial Hospital, 1-1-1

Harunomachi, Yahatahigashi-ku, Kitakyushu 805-8508, Japan. Phone: 81-93-671-9420; Fax: 81-93-671-9605; E-mail:

itaken@d4.dion.ne.jp

Accepted for pulication September 5, 2001.

Revision accepted November 16, 2001. 
A IRWAY management for patients with a laryngeal tumour requires special attention. ${ }^{1,2}$ Large glottic tumours obstruct the glottis and make intubation difficult. When advancing an endotracheal tube (ETT) into the glottis during intubation, the ETT can impact on the tumour and large mobile tumours pushed by the ETT may cause airway obstruction. Advancement of the ETT may slip the broken tumour into the trachea, leading to foreign body or tumour implantation. Bleeding from the damaged tumour may occur. To avoid these problems, careful advancement of the ETT under direct observation is essential in these patients. In patients with an anatomically difficult airway, however, observing tube advancement is difficult. Fibreoptic intubation is a reliable method for a difficult intubation, ${ }^{3-6}$ but advancement of the ETT through the glottis is blind. ${ }^{5,6}$ Previously, we proposed an alternative intubation technique using a fibreoptic bronchoscope (FOB)-video camera system to observe the correct advancement of the ETT in patients with difficult airways. ${ }^{6}$ We describe a case of successful intubation using this technique in a patient with a documented history of anatomically difficult laryngoscopic intubation who had a large, mobile glottic tumour that partially obstructed the glottic opening.

\section{Case report}

A 61-yr-old man $(87 \mathrm{~kg}, 169 \mathrm{~cm})$ with recurrence of a glottic tumour was scheduled for laryngeal microsurgery. Two years previously, the patient had undergone microlaryngoscopy for diagnosis of a small glottic lesion under general anesthesia. The anesthetic record revealed that the patient's trachea had been intubated using a FOB because, using the Macintosh laryngoscope, the anesthesiologist had been unable to lift the epiglottis from the posterior pharyngeal wall sufficiently and the view of the glottis had been Grade 3 according to Cormack and Lehane's classification. Histology demonstrated a squamous cell carcinoma of the glottis, and the patient was treated with irradiation. At the preoperative visit, an experienced anesthesiologist assessed the patient's airway as Mallampati Class 3 with a thyromental distance of $6 \mathrm{~cm}$, one third reduction of atlanto-occipital joint extension, and a mouth opening of $5 \mathrm{~cm}$. On physical examination, the patient had mild inspiratory stridor. Indirect laryngoscopy revealed a large, mobile and pedunculated glottic lesion obstructing the glottic opening. We planned a conventional awake fibreoptic intubation. After counseling the patient regarding the need for awake intubation, he agreed to the procedure.

The patient was premedicated with $0.5 \mathrm{mg}$ atropine $i m$. In the operating room, standard noninvasive

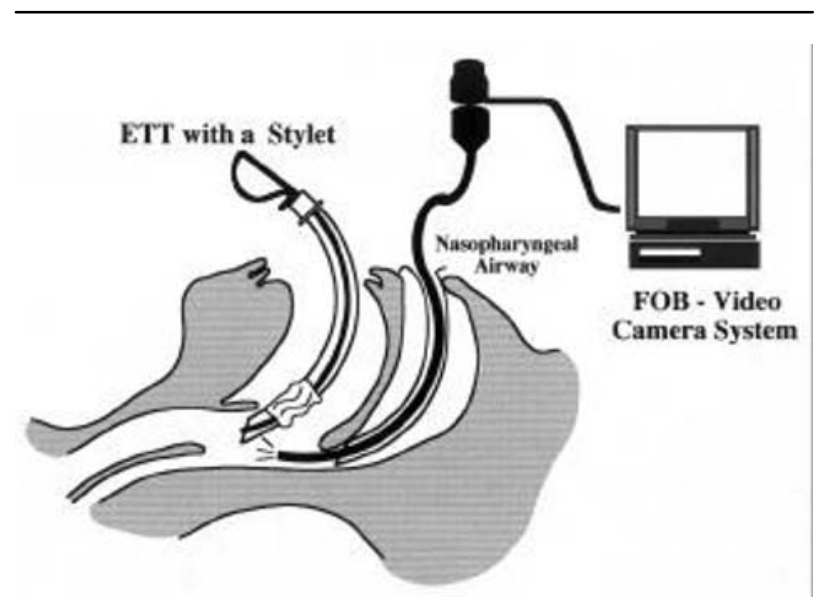

FIGURE Alternative intubation technique using the combination of a fibreoptic bronchoscope (FOB)-video camera system and a styletted endotracheal tube (ETT). The FOB attached to the video camera is passed into the nasopharynx, which provides the view of the larynx on the video monitor. An operator inserts the ETT with the stylet curved as a "hockey stick" into the trachea under video control.

monitors, including electrocardiography, indirect arterial pressure, pulse oximetry, and capnography, were applied and the patient received $2.5 \mathrm{mg}$ midazolam $i v$. Topical anesthesia of the oropharynx was achieved using commercially available $8 \%$ lidocaine spray. A superior laryngeal nerve block was performed with 2 $\mathrm{mL}$ of $1 \%$ lidocaine and the block was repeated on the opposite side. An Ovassapian intubating airway was then inserted into the mouth. The anesthesiologist inserted a $4.9 \mathrm{~mm}$ FOB (BF-P30, Olympus, Tokyo, Japan), passed into a $6.0-\mathrm{mm}$ internal diameter microlaryngeal tube (Mallinckrodt, Athlone, Ireland), through the intubating airway into the oropharynx. Supplemental oxygen was insufflated via the working channel. Endoscopy showed that a large glottic tumour partially obstructed the glottis. Because the space between the tumour and the glottic opening was very narrow, we considered that the ETT advancing over the FOB could push the tumour into the glottis or damage it. So, we changed from a conventional fibreoptic technique to an alternative technique described previously (Figure). ${ }^{6}$ After the intubating airway was removed and the nostril was anesthetized with long cotton-tipped applicators soaked in $4 \%$ lidocaine, a nasopharyngeal airway was inserted. An assistant passed the FOB attached to a video camera (OTV-S5 Olympus) through the nasopharyngeal airway and performed a jaw thrust manoeuver. This pro- 
vided an excellent view of the larynx which was displayed on the monitor screen. The anesthesiologist inserted a $6.0-\mathrm{mm}$ internal diameter cuffed reinforced tube with a stylet in the "hockey stick" configuration into the oropharynx, and carefully advanced the ETT tip into the space between the tumour and the glottic opening under video control. Absence of damage to the tumour and passage of the ETT between the cords were confirmed visually. Successful intubation was confirmed further by capnography and anesthesia induced with propofol $i v$. Oxygen saturation did not decrease below $94 \%$ throughout intubation. The glottic tumour was removed surgically and the trachea was extubated uneventfully. Pathology confirmed recurrence of the glottic carcinoma. Two weeks later, the patient underwent a total laryngectomy.

\section{Discussion}

Most laryngeal tumours occur in the glottic region ${ }^{7}$ and are likely to be pushed, damaged or to bleed during passage of an ETT during intubation. To avoid these problems, careful advancement of the ETT under observation throughout intubation attempts is essential.

Conventional laryngoscopy enables to see the advancement of the ETT under direct vision when a full view of the glottis is obtained. In some patients, direct laryngoscopy cannot provide a full view. Many intubation techniques have been devised for such patients, ${ }^{3,4}$ but few allow a view of the ETT advancement throughout intubation. Even with conventional fibreoptic intubation, advancement of the ETT over the FOB is blind ${ }^{5,6}$ and may impact on a large tumour. ${ }^{5}$ Alternative laryngoscopes, such as the Bullard laryngoscope, the Wuscope, and the Upsherscope, allow visualization of ETT advancement. ${ }^{8}$ With these laryngoscopes, the viewing end of the fibreoptic bundles and the ETT are moved simultaneously, so it may be difficult to obtain a clear view while controlling the ETT tip, especially when the larynx is distorted and obstructed by a large tumour. In contrast, our technique has some useful features. First, with our technique both the operator and assistants can view the glottis and the ETT tip, and therefore the operator can receive assistance while introducing the ETT into the glottis. Second, our technique allows free selection of intubating introducers, including a stylet, a bougie, and a fibrescope, as occasion demands. In our patient, using a stylet, the ETT could be introduced easily through the narrow laryngeal aperture into the trachea. When difficulty in inserting the ETT with the stylet is encountered, forceful advancement should be avoided. Use of a second FOB as an intubating introducer may be useful in this situation. ${ }^{6}$ Finally, view of the glottis via the FOB is not obstructed by manipulation of the ETT into the trachea because our technique allows the FOB and the ETT to be controlled independently. The excellent view obtained helps advance the ETT while avoiding impact on the tumour. A disadvantage of the technique is the necessity to use the nasal route.

In our patient, application of the jaw thrust manoeuver provided a clear fibreoptic view of the glottis and sufficient room to control the ETT by lifting the tongue, the epiglottis and laryngeal soft tissues. ${ }^{9} \mathrm{We}$ did not use a laryngoscope for these purposes because, in some patients with a difficult airway, the laryngoscope cannot lift the epiglottis from the posterior pharyngeal wall sufficiently, expand structures around the glottis, and provide a good fibreoptic view of the glottis. ${ }^{10}$ Topical anesthesia of the airway and conscious sedation with midazolam allowed the successful execution of awake intubation. Adequate topical airway anesthesia suppressed gag and cough reflexes, and was essential to obtain an excellent fibreoptic view and to advance the ETT safely. Sedation should be titrated carefully to avoid exacerbation of airway obstruction caused by loss of muscle tone in patients with large laryngeal tumours.

In summary, this case of known, anatomically difficult intubation had the potential for complications during blind passage of the ETT during conventional fibreoptic intubation. An alternative intubation technique, combining the FOB-video camera system and a styletted ETT, permitted an excellent view of the ETT passage into the glottis. We believe this is a reasonable method to prevent problems associated with a large laryngeal tumour in patients with a difficult airway.

\section{References}

1 McGowan FX. Anesthesia for major head and neck surgery. In: McGoldrick KE (Ed.). Anesthesia for Ophthalmic and Otolaryngologic Surgery.

Philadelphia: W.B. Saunders Co., 1992: 64-89.

2 Donlon JV Jr. Anesthetic and airway management of laryngoscopy and bronchoscopy. In: Benumof JL (Ed.). Airway Management Principles and Practice, lst ed., St. Louis: Mosby, 1995: 666-85.

3 Benumof JL. Management of the difficult adult airway. With special emphasis on awake tracheal intubation. Anesthesiology 1991; 75: 1087-110.

4 Morris IR. Fibreoptic intubation. Can J Anaesth 1994; 41: 996-1008.

5 Ovassapian A. Fiberoptic Endoscopy and the Difficult Airway, 2nd ed. Philadelphia: Lippincott-Raven Publishers, 1996. 
6 Aoyama K, Takenaka I, Sata T, Shigematsu A. Use of the fibrescope-video camera system for difficult tracheal intubation. Br J Anaesth 1996; 77: 662-4.

7 Thawley SE. Cysts and tumors of the larynx. In: Paparella MM, Shumrick DA, Gluckman JL, Meyerhoff WL (Eds.) Otolaryngology, 3rd ed. Philadelphia: WB Saunders Co., 1991; 2307-69.

8 Cooper SD, Benumof JL, Ozaki GT. Evaluation of the Bullard laryngoscope using the new intubating stylet: comparison with conventional laryngoscopy. Anesth Analg 1994; 79: 965-70.

9 Aoyama K, Takaneka I, Nagaoka E, Kadoya T. Jaw thrust maneuver for endotracheal intubation using a fiberoptic stylet (Letter). Anesth Analg 2000; 90: 1457-8.

10 Takenaka I, Aoyama K, Kadoya T, Sata T, Shigematsu $A$. Fibreoptic assessment of laryngeal aperture in patients with difficult laryngoscopy. Can J Anesth 1999; 46: 226-31. 